University of Nebraska - Lincoln

DigitalCommons@University of Nebraska - Lincoln

$11-1-2006$

\title{
The Role of Child Emotional Responsiveness and Maternal Negative Emotion Expression in Children's Coping Strategy Use
}

\author{
Rebecca Goodvin \\ University of Nebraska-Lincoln, rgoodvin@bigred.unl.edu \\ Gustavo Carlo \\ University of Nebraska-Lincoln, carlog@missouri.edu \\ Julia C. Torquati \\ University of Nebraska-Lincoln, jtorquati1@unl.edu
}

Follow this and additional works at: https://digitalcommons.unl.edu/psychfacpub

Part of the Psychiatry and Psychology Commons

Goodvin, Rebecca; Carlo, Gustavo; and Torquati, Julia C., "The Role of Child Emotional Responsiveness and Maternal Negative Emotion Expression in Children's Coping Strategy Use" (2006). Faculty Publications, Department of Psychology. 226.

https://digitalcommons.unl.edu/psychfacpub/226

This Article is brought to you for free and open access by the Psychology, Department of at DigitalCommons@University of Nebraska - Lincoln. It has been accepted for inclusion in Faculty Publications, Department of Psychology by an authorized administrator of DigitalCommons@University of Nebraska - Lincoln. 


\title{
The Role of Child Emotional Responsiveness and Maternal Negative Emotion Expression in Children's Coping Strategy Use
}

\author{
Rebecca Goodvin,* Gustavo Carlo, and Julia Torquati \\ University of Nebraska-Lincoln
}

\begin{abstract}
This study examined the additive and interactive effects of children's trait vicarious emotional responsiveness and maternal negative emotion expression on children's use of coping strategies. Ninety-five children (mean age $=5.87$ years) and their mothers and teachers participated in the study. The mothers reported on their own negative emotion expression and the children's empathic concern and personal distress tendencies. The mothers and teachers reported on the children's use of avoidant, support-seeking, and aggressive-venting coping strategies. Empathic concern was positively associated with the children's use of support seeking and negatively associated with the children's use of aggressive venting, whereas personal distress showed the opposite pattern of associations. Maternal negative emotion expression moderated some associations between the children's emotional responsiveness and coping. These findings support the hypothesis that children's tendencies to experience empathic concern or personal distress indicate functionally distinct styles of emotional arousal that may have broader consequences for socially competent behavior in response to normative stressors.
\end{abstract}

Keywords: emotional responding, empathy, coping, family emotion expression

Changes in social contexts and interactions in early childhood inevitably give rise to challenging personal and interpersonal situations, highlighting the importance of children's ability to cope adaptively with stressful encounters in their daily lives. How young children cope with stressors may also have longer-term implications for their social adjustment (Compas, Connor-Smith, Saltzman, Thomsen \& Wadsworth, 2001; Eisenberg, Fabes, Carlo \& Karbon, 1992; Eisenberg, Fabes \& Guthrie, 1997; Kliewer \& Sandler, 1993; Rutter, 1996). However, children enter the school years with substantial variability in their responses to stressful situations. It is thus of considerable importance to examine the individual and contextual factors associated with young children's use of adaptive coping strategies. The goal of the current study was to examine the additive and interactive effects of maternal emotion expression (EE) and children's own emotional responsiveness on children's coping strategies.

*Corresponding author - Department of Psychology, University of Nebraska-Lincoln, 238 Burnett Hall, Lincoln, NE 68588-0308. Email: rgoodvin@bigred.unl.edu 
Coping has been defined as 'conscious, volitional efforts to regulate emotion, cognition, behavior, physiology, and the environment in response to stressful events or circumstances' (Compas et al., 2001). Eisenberg and colleagues have proposed three dimensions of children's coping: problem-focused coping, emotion-focused coping and the regulation of emotionally driven behavior (e.g., Eisenberg et al., 1997; Eisenberg, Fabes, Carlo \& Karbon 1992). Problem-focused coping is aimed at changing the environment or stressor. Emotion-focused coping includes strategies aimed at adapting to the stressor by regulating one's experience of stress. Coping with emotionally driven behavior is targeted at regulating the behavior that may be caused by negative emotion rather than at changing the stressor or regulating the experience of stress. In a recent review of the literature regarding child and adolescent coping, Compas et al. (2001) found that engagement coping and problem-focused coping are, in general, associated with more positive psychological adjustment whereas disengagement coping and emotion-focused coping are associated with less positive psychological adjustment. However, research on children's coping has indicated that children enlist a number of strategies to cope with stressful situations and that, at least for children and adolescents, broad unidimensional categories, such as emotion- and problem-focused coping (Lazarus \& Folkman, 1984), do not adequately capture the variation in coping strategies enlisted by children (e.g., Ayers, Sandler, West \& Roosa, 1996). Another approach to the study of coping is to examine children's specific strategies of response to stressors and to locate those strategies within a larger theoretical framework. The current study includes mother and teacher reports of three coping strategies used by young children: avoidance, support seeking, and emotional or aggressive venting.

Avoidance can be considered an emotion-focused coping response, and support seeking includes elements of both problem- and emotion-focused coping. Aggressive venting represents a failure to regulate emotionally driven behavior. This framework for coping strategies is consistent with those proposed by Eisenberg and others (e.g., Eisenberg et al., 1997; Eisenberg, Fabes, Carlo \& Karbon 1992; Kliewer, 1991; Miller, Kliewer, Hepworth \& Sandler, 1994). Thus, support seeking is considered a more adaptive coping strategy than either avoidance or aggressive venting (see Compas et al., 2001).

Although there are undoubtedly many factors contributing to children's use of adaptive coping strategies, emotional tendencies play a central role in coping. Children who, in general, experience some negative emotional arousal but do not become overly aroused during stressful situations may be more capable of engaging in adaptive strategies for coping. Children who tend to experience high levels of distress, on the other hand, may become overly aroused and unable to select or engage in an effective coping strategy, and may instead express their negative emotion ineffectively, or in a way that does not bring them the needed support. Alternatively, children who become overly distressed may be unable to engage in coping with the situation at all and instead may disengage as they avoid thinking about or dealing with the stressor (Eisenberg \& Fabes, 1991, 1994; Eisenberg, Fabes, Miller, Shell, Shea \& May-Plumlee, 1990; Eisenberg, Fabes, Nyman, Bernzweig \& Pinuelas, 1994; Lengua \& Long, 2002). In short, children who generally experience higher levels of negative emotion may use different, and perhaps less effective, coping strategies than children who experience more manageable levels of arousal (Calkins \& Johnson, 1998; Eisenberg et al., 1997; Eisenberg, Fabes, Carlo \& Karbon, 1992; Rothbart \& Bates, 1998).

One aspect of children's emotionality that has been little explored in terms of its potential association with coping is trait vicarious emotional responding. Typically defined as chil- 
dren's emotional responsiveness to others' distress or negative emotion, vicarious emotional responding can also be considered indicative of a more general pattern of emotional tendencies (Eisenberg \& Fabes, 1998). Children's empathic concern or sympathy is often associated with other-focused emotion that leads to constructive prosocial or helping responses, and is negatively associated with aggression (e.g., Fabes, Eisenberg, Karbon, Troyer \& Switzer, 1994; Miller \& Eisenberg, 1988). Personal distress, however, is associated with overarousal in response to others' experience, self-focused discomfort or anxiety, and low levels of helping behavior (Eisenberg \& Fabes, 1991, 1998; Hoffman, 1975). Instead, children who are prone to personal distress in response to the negative emotions of others may respond with aggressive behavior, or avoid the stressful situation altogether when it is possible to do so (Batson, 1991; Eisenberg et al., 1990; Eisenberg \& Fabes, 1991; Volling, 2001). Although helping behavior is an other-directed response, in comparison with avoidance or aggressing, it represents an active effort to aid another child in coping with a stressor and should have the effect of ameliorating the helper's distress. If it is indeed the case that empathic concern and personal distress represent two different patterns of emotional tendency, with very different functional values, we would expect associations between coping, a subset of regulatory behaviors and vicarious emotional responding. Moreover, as situations eliciting distress in young children are likely to involve social interaction, and potentially the emotional arousal of others, an examination of children's vicarious emotional responding and coping is warranted.

An examination of children's emotional tendencies is, however, only part of the picture in understanding children's use of coping strategies. It is also necessary to acknowledge the role of children's environment in terms of the emotional context of the family as a significant influence on both emotional responding and coping strategies. Parents' expressiveness affects the general emotional climate of the home, and within the family children identify how and in what situations to express emotion, which emotions are appropriate to express, and how others are likely to respond to their emotional displays (Dunsmore \& Halberstadt, 1997; Eisenberg, Cumberland \& Spinrad, 1998). Emotion expression within the family may thus influence children's emotionality directly (Halberstadt, Crisp \& Eaton, 1999; Halberstadt \& Eaton, 2002), and may influence children's coping both directly and indirectly by moderating the association between children's emotionality and their use of coping strategies.

Family EE is typically divided into positive, negative dominant and negative submissive (Halberstadt, Cassidy, Stifter, Parke \& Fox, 1995). Positive expressiveness includes emotions such as pride, happiness or appreciation. Negative dominant expression includes angry and hostile emotion, typically outwardly directed, whereas negative submissive expression includes inwardly directed emotions such as sadness and shame. Family norms for the expression of negative emotion, in particular, may be linked to children's coping because of the importance of understanding and managing negative emotions for other areas of children's social and emotional development (Thompson, 1998). For example, it is the understanding of negative emotion that appears to differentiate young children on other indicators of socio-emotional development such as attachment security (e.g., Laible \& Thompson, 1998). Moreover, coping occurs by definition under stressful circumstances in which the child is experiencing negatively valenced emotion. Finally, associations of children's outcomes with negative EE within the family are complex and previous research examining these links has been inconsistent (Halberstadt et al., 1999). Thus, in the current study we chose to focus on the role of negative EE as an influence on children's coping strategy use. 
In a series of studies examining parental expression of emotion and third- and sixth-grade children's emotional responding, Eisenberg and colleagues reported that children's vicarious emotional response to a sympathy-inducing film was related to their parents' self-reported EE, although findings differed somewhat by child gender. Specifically, girls' expression of facial concerned attention, thought to indicate an optimal level of arousal, was positively associated with maternal negative submissive EE, whereas maternal negative dominant EE was positively associated with facial distress, indicating overarousal. For boys, however, higher levels of negative dominant EE were associated with lower levels of concerned attention (Eisenberg, Fabes, Carlo, Troyer, Speer, Carbon et al., 1992). For both boys and girls, self-reported empathic concern of the same-sex parent was negatively associated with facial distress (Eisenberg, Fabes, Schaller, Carlo \& Miller, 1991). Cummings and colleagues have reported that infants respond to family anger with behavioral distress, with distress being more likely with repeated exposure (Cummings, Zahn-Waxler \& Radke-Yarrow, 1981), and have shown that young children (4- to 5-year-olds) display increased distress during a staged argument episode (Cummings, 1987). Recently, Valiente, Eisenberg, Shepard, Fabes, Cumberland and Losoya et al. (2004) reported that maternal negative EE is positively associated with children's facial distress during a distressing attachment-related film, and did not find differences for dominant and submissive negative emotion. In sum, although negative EE within the family and vicarious emotional responding in young children appear to be linked, links may differ by the type of negative emotion (submissive or dominant), and further exploration of these associations is needed.

Prior research also suggests several paths by which family EE may influence children's coping strategies. Firstly, there may be a direct link between negative EE and children's coping. Children may develop emotional response patterns such as those displayed in the family by observing their parents' strategies for addressing their own negative emotions, through their parents' focus on specific emotions and coping strategies in conversation, and through their parents' response to children's own emotions (Eisenberg et al., 1998). Although associations of negative EE and children's coping have not been extensively examined, the research that does exist indicates links between parents' reactions to children's negative emotions and children's coping. In general, minimization of children's negative emotions and punitive or hostile reactions to children's negative emotions are associated with lower levels of children's constructive coping and higher levels of avoidant or aggressive coping (e.g., Carson \& Parke, 1996; Eisenberg \& Fabes, 1994; Eisenberg, Fabes, Carlo \& Karbon, 1992; Eisenberg, Fabes \& Murphy, 1996). Recently, Valiente, Fabes, Eisenberg and Spinrad (2004) reported that mothers' negative emotional expression, and in particular negative dominant emotional expression, is negatively associated with children's constructive coping.

Previous research also indicates that family EE is related to child emotion regulation (Halberstadt \& Eaton, 2002; Halberstadt et al., 1999). Families' expression of positive emotion is reliably associated with greater emotion regulation abilities in young children. However, questions remain regarding the role of families' negative EE in the development of emotion regulation (Halberstadt \& Eaton, 2002). Prior findings have again been inconsistent, with negative emotional expression positively related to emotion regulation in one study (Greenberg, Lengua, Coie \& Pinderhughes, 1999) and negatively related to emotion regulation in another (Garner, 1995), although this latter finding emerged for negative submissive emotion only. A recent longitudinal study indicates that maternal reactions of distress and punitiveness in re- 
sponse to children's negative emotions predict lower regulation in children two years later, at eight to 10 years of age (Eisenberg, Fabes, Shepard, Guthrie, Murphy \& Reiser, 1999).

Secondly, children's emotional tendencies and negative family EE may interact to influence children's coping. More specifically, it is likely that family emotional expression moderates the influence of children's emotionality on their coping. Children may respond to the general emotional climate of the home differently depending on their own emotional tendencies. For example, a child who is prone to distress and overarousal may be more sensitive to negative emotion in the home and learn aggressive ways to express emotions. Further, in an environment of high levels of angry and hostile behavior, children who are already prone to overarousal may be more likely to disengage from the situation when stressors exceed their capacity for emotion regulation. Moreover, these children may learn less regarding emotions and ways to handle those emotions constructively (Eisenberg et al., 1998). This notion is consistent with the position of temperament theorists that children's temperamental emotionality interacts with the environment to influence developmental outcomes (Rothbart \& Bates, 1998), and is also in agreement with Eisenberg et al.'s body of work examining children's emotional tendencies, regulation, and family emotion socialization as joint influences on social functioning (e.g., Eisenberg et al., 1998; Eisenberg, Fabes, Guthrie \& Reiser, 2000). However, little previous research has examined interactive influences of socialization context and children's traits on the use of coping strategies.

In one study, Valiente, Fabes et al. (2004) found that mothers' (but not fathers') negative submissive expressiveness moderated associations between children's experience of stress and their use of constructive coping strategies, although these results reached only marginal significance. The association between children's stress and constructive coping was more negative as mothers' reported lower levels of negative submissive EE. Parental negative dominant emotion, on the other hand, exerted only a main effect on children's constructive coping, with higher levels of maternal negative dominant emotion associated with lower levels of children's constructive coping regardless of the level of stress experienced by the child. In a longitudinal study, Gilliom, Shaw, Beck, Schonberg, and Lukon (2002) found that the interaction of children's difficult temperament and maternal positive control at 18 months predicted their use of some, but not all, coping strategies in response to a frustrating situation at the age of 3.5. Along with research reviewed above, these studies suggest that children's emotional responsiveness in stressful encounters, EE within the family, and the interaction of these influences, are likely to be associated with children's use of coping strategies.

Thus, the primary purpose of the study was to examine children's vicarious emotional tendencies and mothers' negative EE, and their interaction, as predictors of children's coping strategies. Specifically, this study examined the unique contributions of children's trait empathic concern and personal distress, and their mothers' negative dominant and negative submissive EE, and their interactions, to three coping strategies used by young children: avoidance, support seeking and aggressive venting. Based on previous research examining links between emotional responsiveness and helping behavior, we expected that children's empathic concern would be positively associated with use of adaptive support-seeking strategies and negatively associated with less adaptive coping strategies avoidance and aggressive venting. Conversely, we expected personal distress to be positively associated with avoidant coping and aggressive venting and negatively associated with support seeking. 
Based on prior research examining family negative EE and children's coping and emotion regulation, we expected direct positive associations between maternal negative dominant EE and children's avoidant coping and aggressive venting. In addition, we predicted that maternal EE would moderate these links. For example, children whose mothers report high levels of negative dominant EE, as compared with low levels of negative dominant EE, would be more likely to exhibit positive associations between personal distress and both avoidant coping and aggressive venting. In contrast, maternal negative dominant EE was not expected to moderate associations of personal distress and support seeking, or associations between empathic concern and coping. However, specific a priori predictions regarding maternal negative submissive EE as a direct influence on children's coping, or as a potential moderator of the relations between empathic concern and personal distress and coping, were difficult to develop, given the mixed prior research findings; thus, these tests were considered exploratory.

\section{Method}

\section{Participants}

Ninety-five children (49 girls; mean age $=5.87, S D=1.3$, range 3.3 to 8.6 years) and their mothers and teachers $(\mathrm{N}=86)$ participated in this study. Preschool children (40 percent) were recruited from a university preschool center, and school-age children (60 percent) were recruited from 20 after-school programs in a midsize, mid-western community. The majority of the children were European-American (80 percent); the remaining children were African-American (3 percent), Asian-American (2 percent), Latino/Hispanic-American (2 percent), Native American (5 percent) and others ( 8 percent). Although information on the socioeconomic status of the families was not collected, the children were recruited from programs serving families from a wide range of income levels. Most children (76 percent) were living in a household with both biological parents; 13 percent were living with a single biological parent and 4 percent were living with one biological parent and one step-parent. The mean level of maternal education was four years of college, with 11 percent having completed high school, 33 percent having completed some college, 36 percent with a bachelor's degree and 20 percent with postgraduate education.

\section{Procedure}

The families were recruited by sending letters to parents through a university preschool program and by talking with parents at the after-school program sites. The mothers of the preschool children completed questionnaires at home, and the parents of the school-age children completed questionnaires at a university office. The mothers completed surveys of demographic information, child emotionality, child coping strategies and their own EE. At their convenience, the teachers of the study children completed the survey of the child coping strategies.

\section{Measures}

Maternal EE. Mothers completed Halberstadt et al.'s (1995) family expressiveness questionnaire. Two 10-item scales were included: negative submissive expressiveness (e.g., 'Going to pieces when tension builds up'; $\alpha=.70$ ) and negative dominant expressiveness (e.g., 'Blam- 
ing one another for family troubles'; $\alpha=.83)$. The mothers were asked to indicate on a ninepoint scale ( 1 = not at all frequently; 9 = very frequently) the frequency with which they expressed each of the specific emotion-related behaviors.

Child Emotionality. The mothers completed the interpersonal reactivity index (Davis, 1980), from which two seven-item scales were included: empathic concern (e.g., 'My child often has tender, concerned feelings for people less fortunate than him/her'; $\alpha=.77$ ) and personal distress (e.g., 'In emergency situations, my child feels apprehensive and ill-at-ease'; $\alpha=.76$ ). The mothers indicated on a five-point scale $(1=$ 'Does not describe my child well'; $5=$ 'Describes my child very well') how well each statement described her child's behavior.

Child Coping Strategies. The mothers and teachers completed a measure of the children's coping strategies. This measure was adapted from several coping measures commonly used with children in preschool, middle childhood, and adolescence (e.g., Band \& Weisz, 1988; Curry \& Russ, 1985; Gamble, 1994; Spirito, Stark \& Williams, 1988; Wertlieb, Weigel \& Feldstein, $1987)$ and asks the reporter to indicate on a four-point scale $(1=$ never; $4=$ often $)$ how often a child uses a strategy when upset or when in a challenging situation. The measure includes three subscales: avoidance (e.g., 'stay away from the problem or situation'; parent report, $\alpha=$ .52 ; teacher report, $\alpha=.54$ ); support seeking (e.g., 'ask an adult for help'; parent report, $\alpha=$ .74 ; teacher report, $\alpha=.84$ ); and aggressive venting (e.g., 'yell or call someone a name'; parent report, $\alpha=.68$; teacher report, $\alpha=.82$ ). To increase reliability, one item was dropped from the teacher-report avoidance subscale. The items are presented in Appendix A.

\section{Results}

\section{Preliminary Analyses}

Descriptive data for study variables are presented in Table 1. Because some researchers have found age and gender differences in vicarious emotional responding and coping, and to examine possible age and gender differences in the criterion variables (parent and teacher reports of child coping), preliminary multiple regressions were performed, entering age and gender in the first step, and the age $\times$ gender interaction in the second step. Neither child age nor the interaction of child age and gender was a significant predictor of parent or teacher reports of child coping strategies. Gender significantly predicted teacher reports of child venting, with teachers reporting significantly higher venting for boys than for girls $(b=-.60, p<.01)$. Because gender was a significant predictor for only one teacher-report variable, it was not included as a control in further analyses.

\section{Intercorrelations Among Study Variables}

Table 2 shows the intercorrelations among child age and gender, parent-reported child empathic concern and personal distress, maternal negative EE and parent- and teacher-reported avoidance, support seeking, and venting. There was a significant positive correlation between child age and empathic concern, and, as indicated in preliminary regressions, a significant negative correlation between child gender and teacher reported venting. Among predictor variables 
Table 1. Descriptive Statistics for Child Emotionality, Maternal Negative Emotion Expression (EE) and Child Coping

\begin{tabular}{|c|c|c|c|}
\hline Variable & Mean & $S D$ & Range \\
\hline \multicolumn{4}{|l|}{ Child emotionality } \\
\hline Empathic concern & 3.85 & .64 & $2.14-5.00$ \\
\hline Personal distress & 2.90 & .71 & $1.14-4.71$ \\
\hline \multicolumn{4}{|l|}{ Maternal EE } \\
\hline Negative dominant & 3.77 & 1.20 & $1.40-8.50$ \\
\hline Negative submissive & 5.43 & 1.08 & $3.20-8.50$ \\
\hline \multicolumn{4}{|l|}{ Child coping } \\
\hline Avoidance-parent report & 2.52 & .46 & $1.60-3.67$ \\
\hline Support seeking_-parent report & 3.19 & .41 & $1.63-4.00$ \\
\hline Venting_parent report & 2.56 & .72 & $1.00-4.00$ \\
\hline Avoidance-teacher report ${ }^{\mathrm{a}}$ & 2.56 & .56 & $1.25-4.00$ \\
\hline Support seeking —-teacher report ${ }^{\mathrm{a}}$ & 2.95 & .56 & $1.13-4.00$ \\
\hline Venting-teacher report ${ }^{\mathrm{a}}$ & 2.01 & 1.01 & $1.00-4.00$ \\
\hline
\end{tabular}

$\mathrm{N}=93$.

a Teacher-report data, $\mathrm{N}=86$.

(child emotionality and maternal negative EE), only one significant correlation, between negative dominant and negative submissive EE, was found.

The correlations between child emotionality and coping variables indicated that the children's empathic concern was related positively to both parent- and teacher-reported support seeking and related negatively to teacher-reported venting. Personal distress was related negatively to parent-reported support seeking and related positively to parent-reported venting.

The correlations between maternal EE and child coping variables indicated that maternal negative dominant EE was positively associated with both parent- and teacher-report child support seeking and negatively associated with teacher-report child venting. Maternal negative submissive EE was positively associated with parent report of child venting.

The correlations among coping variables indicated a negative association between support seeking and venting for both parent- and teacher-report data, and a negative association between avoidance and support seeking for teacher-report data. Further, there were positive associations between parent- and teacher-report support seeking, and between parent- and teacher-report venting. Finally, there was a negative association between parent-reported support seeking and teacher-reported venting.

The correlations conducted separately for younger and older children (split at the age of five to separate the preschool from the elementary school children) largely yielded the same pattern of results, although given reduced sample sizes, not all correlations remained significant. Negative correlations between parent-reported support seeking and both parent- and teacherreported venting held only for the older children; these correlations were in the opposite direction, but not significant, for the younger children. Additionally, for younger but not older children, a negative correlation emerged for personal distress and teacher-reported venting. 


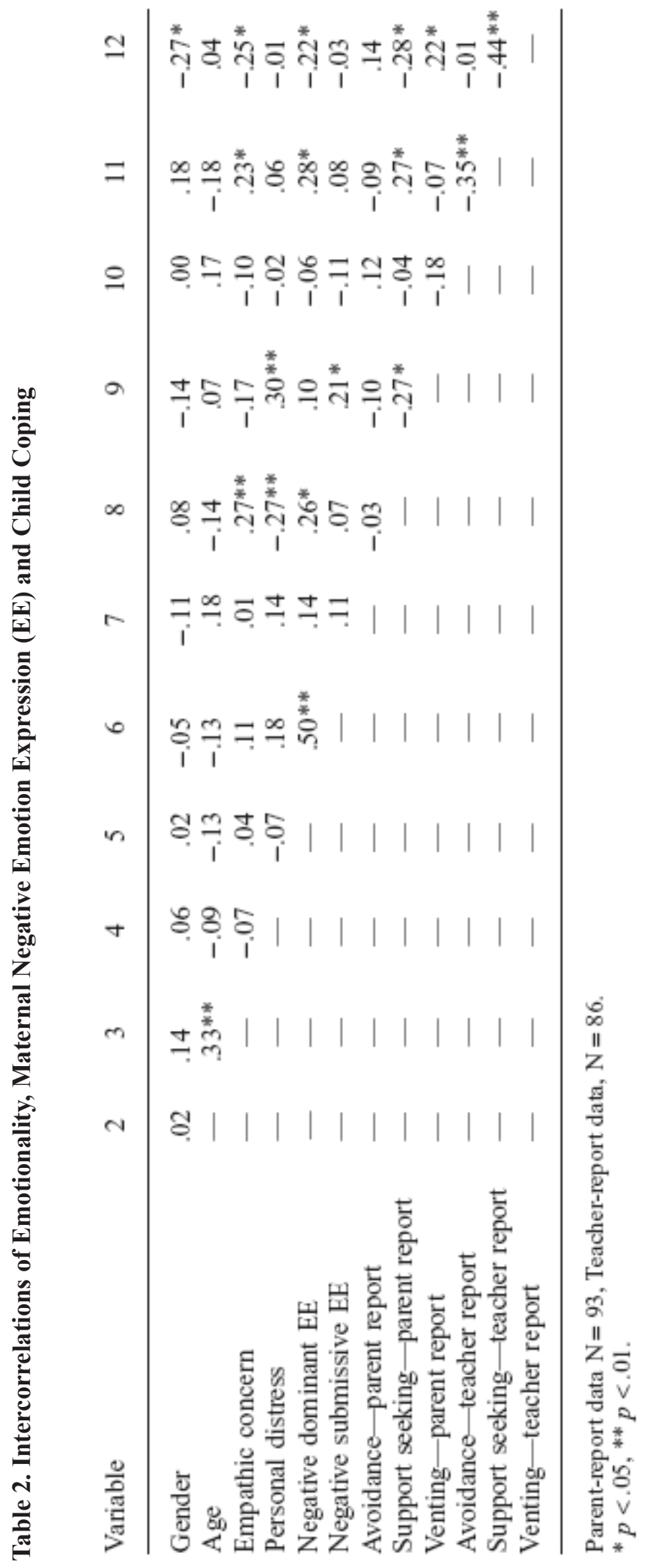


Table 3. Regression Weights (Standardized Regression Weights) for Models Predicting Parent-Reported Child Coping Style

\begin{tabular}{|c|c|c|c|}
\hline \multirow[b]{2}{*}{ Model } & \multicolumn{3}{|c|}{ Parent-Reported Child Coping Style } \\
\hline & Avoidance & Support Seeking & Venting \\
\hline \multicolumn{4}{|l|}{ Empathic concern } \\
\hline 1. Age & $.08(.24)^{*}$ & $-.07(-.22)^{*}$ & $.10(.17)$ \\
\hline Empathic concern (EC) & $-.06(-.09)$ & $.20(.32)^{* *}$ & $-.26(-.23)^{*}$ \\
\hline Negative dominant EE (ND) & $.06(.17)$ & $.07(.21)+$ & $.04(.07)$ \\
\hline $\mathrm{EC} \times \mathrm{ND}$ & $.04(.09)$ & $.02(.05)$ & $.14(.19)+$ \\
\hline$R^{2}$ & .08 & $.17 * *$ & $.09+$ \\
\hline 2. Age & $.09(.25)^{*}$ & $-.08(-.25)^{*}$ & $.12(.21)+$ \\
\hline $\mathrm{EC}$ & $-.05(-.06)$ & $.22(.34)^{* * *}$ & $-.27(-.24)^{*}$ \\
\hline Negative submissive EE (NS) & $.05(.11)$ & $.00(.00)$ & $.17(.25)^{*}$ \\
\hline $\mathrm{EC} \times \mathrm{NS}$ & $.15(.25)^{*}$ & $.02(.03)$ & $.16(.17)$ \\
\hline$R^{2}$ & $.12 *$ & $.12 *$ & $.14 *$ \\
\hline \multicolumn{4}{|l|}{ Personal distress } \\
\hline 3. Age & $.08(.22)^{*}$ & $-.04(-.13)$ & $.07(.12)$ \\
\hline Personal distress (PD) & $.07(.12)$ & $-.17(-.30)^{* *}$ & $.33(.32)^{* *}$ \\
\hline (ND) & $.04(.11)$ & $.05(.15)$ & $.05(.09)$ \\
\hline $\mathrm{PD} \times \mathrm{ND}$ & $.13(.25)^{*}$ & $.10(.22)^{*}$ & $.09(.10)$ \\
\hline$R^{2}$ & $.14^{*}$ & $.19^{* *}$ & $.13 *$ \\
\hline 4. Age & $.07(.21)$ & $-.05(-.15)$ & $.07(.12)$ \\
\hline $\mathrm{PD}$ & $.06(.09)$ & $-.19(-.32)^{* *}$ & $.27(.27)^{*}$ \\
\hline NS & $.03(.08)$ & $.03(.09)$ & $.10(.15)$ \\
\hline $\mathrm{PD} \times \mathrm{NS}$ & $.06(.12)$ & $.04(.09)$ & $.09(.11)$ \\
\hline$R^{2}$ & .07 & $.12^{*}$ & $.15^{*}$ \\
\hline
\end{tabular}

$\mathrm{N}=93$.

$+p<.10, * p<.05, * * p<.01$.

Regression Models Predicting Children's Coping Strategies

Because of the relatively wide age range of children in this study and the significant association between child age and empathic concern, child age was entered into all regression models to control for its effects in main analyses. To predict the children's use of coping strategies from child emotionality, maternal EE, and their interaction, three sets of four simultaneous multiple regression models were constructed for both parent and teacher reports of child coping. As outlined by Aiken and West (1991), the interaction terms were calculated by centering variables and then computing the product of each combination of child emotionality and maternal EE variables. Tables 3 and 4 show regression models for parent and teacher reports of child coping, respectively. 
Table 4. Regression Weights (Standardized Regression Weights) for Models Predicting Teacher-Reported Child Coping Style

Teacher-Reported Child Coping Style

\begin{tabular}{|c|c|c|c|}
\hline Model & Avoidance & Support Seeking & Venting \\
\hline \multicolumn{4}{|l|}{ Empathic concern } \\
\hline 1. Age & $.10(.21)$ & $-.11(-.24)^{*}$ & $.09(.11)$ \\
\hline Empathic concern (EC) & $-.15(-.17)$ & $.27(.31)^{* *}$ & $-.42(-.26) *$ \\
\hline Negative dominant EE (ND) & $.01(.03)$ & $.09(.20)+$ & $-.12(-.15)$ \\
\hline $\mathrm{EC} \times \mathrm{ND}$ & $-.05(-.09)$ & $-.03(-.05)$ & $-.12(-.11)$ \\
\hline$R^{2}$ & .06 & $.17 * *$ & $.13 *$ \\
\hline 2. Age & $.09(.21)$ & $-.13(-.29)^{*}$ & $.15(.18)$ \\
\hline $\mathrm{EC}$ & $-.15(-.17)$ & $.30(.35)^{* *}$ & $-.52(-.32)^{* *}$ \\
\hline Negative submissive EE (NS) & $-.03(-.05)$ & $-.02(-.03)$ & $.05(.06)$ \\
\hline $\mathrm{EC} \times \mathrm{NS}$ & $-.03(-.04)$ & $.07(.10)$ & $-.11(-.08)$ \\
\hline$R^{2}$ & .06 & $.14 *$ & .10 \\
\hline \multicolumn{4}{|l|}{ Personal distress } \\
\hline 3. Age & $.06(.14)$ & $-.05(-.11)$ & $.01(.01)$ \\
\hline Personal distress (PD) & $.01(.02)$ & $.03(.04)$ & $-.01(-.01)$ \\
\hline (ND) & $.03(.06)$ & $.09(.20)$ & $-.14(-.17)$ \\
\hline $\mathrm{PD} \times \mathrm{ND}$ & $-.11(-.19)$ & $.06(.10)$ & $-.14(-.12)$ \\
\hline$R^{2}$ & .05 & .10 & .06 \\
\hline 4. Age & $.06(.14)$ & $-.08(-.17)$ & $.05(.06)$ \\
\hline $\mathrm{PD}$ & $-.01(-.01)$ & $.03(.04)$ & $-.03(-.02)$ \\
\hline NS & $-.05(-.10)$ & $.03(.05)$ & $-.03(-.03)$ \\
\hline $\mathrm{PD} \times \mathrm{NS}$ & $.01(.02)$ & $-.02(-.03)$ & $.05(.05)$ \\
\hline$R^{2}$ & .03 & .04 & .01 \\
\hline
\end{tabular}

$\mathrm{N}=86$.

$+p<.10, * p<.05, * * p<.01$.

Two models predicting the children's use of parent-reported avoidant coping were significant. In Model 2, predicting child avoidant coping from empathic concern and maternal negative submissive emotion, both age and the interaction of empathic concern and maternal negative submissiveness emerged as significant predictors, $F(4,85)=2.80$. The significant interaction indicates that the slope of the association between child empathic concern and avoidant coping was significantly more positive in the context of higher maternal negative submissive EE. Similarly, in Model 3, predicting child avoidant coping from personal distress and maternal negative dominant EE, both age and the interaction of personal distress and maternal negative dominant EE emerged as significant predictors, $F(4,85)=3.58$. The slope of the association between child personal distress and avoidant coping was significantly more positive in the context of higher maternal negative dominant EE. None of the models predicting teacher-reported avoidant coping were significant. 


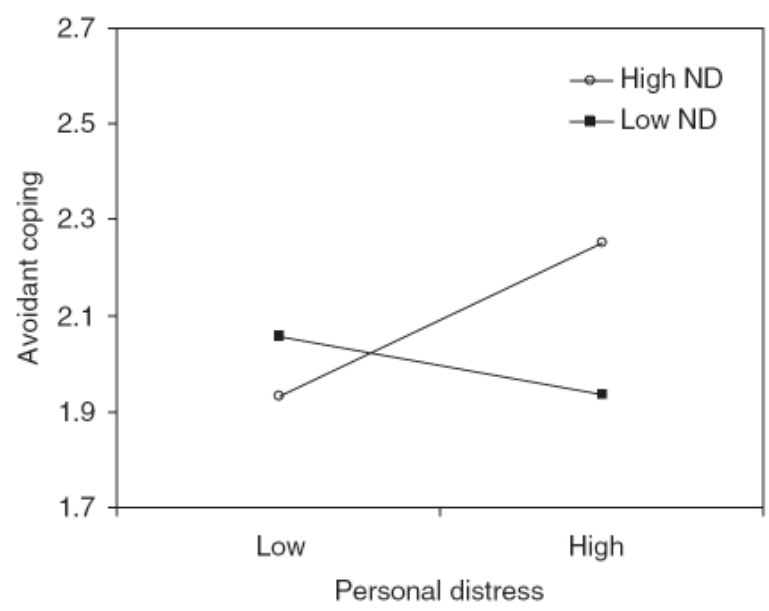

Figure 1. Interaction of Personal Distress and Maternal Negative Dominant Emotion to Predict Child Avoidant Coping.

Note: $\mathrm{ND}=$ Negative dominant. High ND slope is significant, $t=2.44, p=.017$; low ND slope is not significant.

According to procedures detailed by Aiken and West (1991), follow-up $t$-tests were conducted for significant interaction terms to examine individual regression slopes as predictors of child avoidant coping. After centering according to the group mean, the interaction was plotted by using values corresponding to the mean $-1 S D$ (low), and the mean $+1 S D$ (high). In the interaction of personal distress and maternal negative dominant EE predicting child avoidant coping, the regression slope for high maternal negative dominant EE was significant ( $t=$ 2.44, $p<.05)$. As child personal distress and maternal negative dominant EE increase, child avoidant coping increases (see Figure 1). In the interaction of empathic concern and maternal negative submissive EE predicting child avoidant coping, neither of the individual slopes was significant (see Figure 2). All four parent-report models and two teacher-report models predicting children's use of support-seeking coping strategies were significant. Parent and teacher models including child empathic concern showed the same pattern, with child age negatively predicting support seeking, and empathic concern positively predicting support seeking, $F(4,85)=4.46$ for Model 1 , and $F(4,85)=3.01$ for Model 2 with parent-report support seeking; $F(4,74)=3.71$ for Model 1 , and $F(4,74)=3.12$ for Model 2 with teacher-report support seeking. For parent-report models including child personal distress, personal distress emerged as a significant negative predictor of support seeking, $F(4,85)=5.02$ for Model 3 , and $F(4,85)$ $=2.80$ for Model 4 . Finally, the interaction of child personal distress and maternal negative dominant EE was positive and significant, so that the slope of the association between child personal distress and support seeking was significantly more positive in the context of higher maternal negative dominant EE.

A follow-up test of this interaction was conducted using the procedures described above. For the interaction of child personal distress and maternal negative dominant emotion predicting child support seeking, the regression slope for low maternal negative submissive EE was significant $(t=-3.07, p<.01)$. As child personal distress increases and maternal negative dominant EE decreases, child support seeking increases (see Figure 3). 


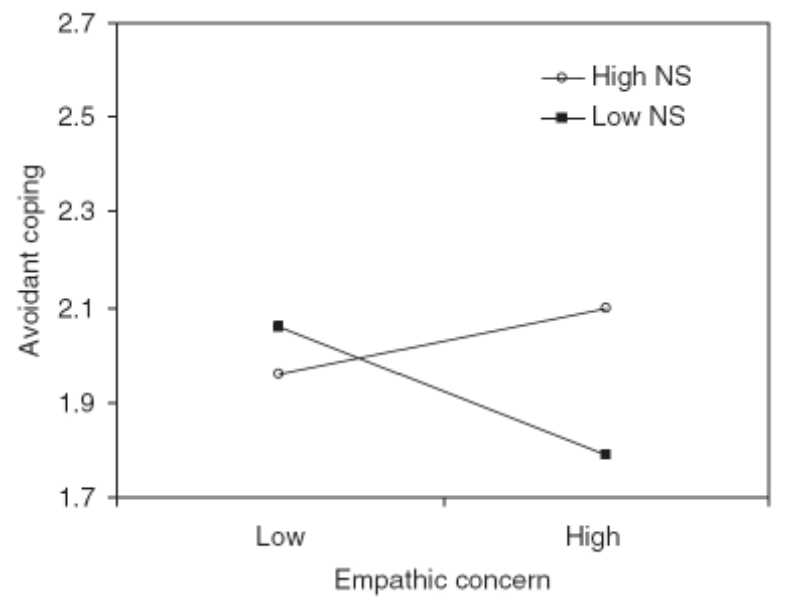

Figure 2. Interaction of Empathic Concern and Maternal Negative Submissive Emotion to Predict Child Avoidant Coping.

Note: NS = Negative submissive. Neither of the individual regression slopes is significant.

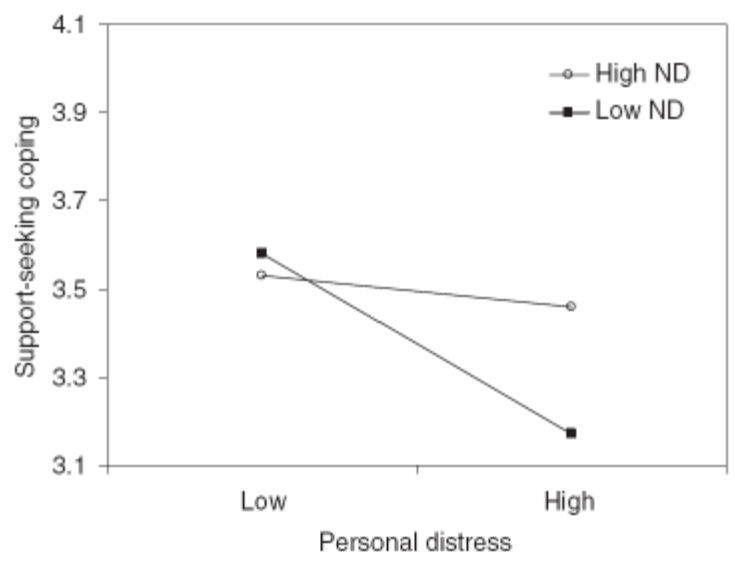

Figure 3. Interaction of Personal Distress and Maternal Negative Dominant Emotion to Predict Child Support-Seeking Coping.

Note: $\mathrm{ND}=$ Negative dominant. High ND slope is not significant; low ND slope is significant, $t=-$ $3.07, p=.001$.

Models predicting children's use of aggressive-venting coping strategies were significant primarily for parent reports of children's venting. However, empathic concern emerged as a significant negative predictor of child aggressive venting across both models for parent- and teacher-report data; Model 2 was significant overall for parent-report venting, $F(4,85)=3.41$, and Model 1 was significant overall for teacher-report venting, $F(4,74)=2.63$. Additionally, maternal negative submissive EE positively predicted child venting in Model 2 with parent-report data. Both models predicting parent-reported child venting from personal distress were significant, with personal distress emerging as a significant predictor in each model, $F(4,85)=$ 3.29 for Model 3, and $F(4,85)=3.75$ for Model $4 .^{1}$ 


\section{Discussion}

This study was designed to examine the additive and interactive effects of children's trait vicarious emotional responding and maternal negative EE for children's use of coping strategies. Overall, the study found that both empathic concern and personal distress related in consistent ways to the children's coping. In general, the higher children were rated in empathic concern, the more likely they were to use support-seeking coping strategies and the less likely they were to use aggressive-venting coping strategies. These findings were consistent across both parent and teacher reports of the children's coping. In contrast, the higher children were rated in personal distress, the more likely they were to use aggressive venting and the less likely they were to use support-seeking coping. These findings are consistent with studies indicating that children's other-directed helping and aggressive behavior are related to their trait vicarious emotional responding (e.g., Eisenberg \& Fabes, 1991, 1998; Fabes et al., 1994; Hoffman, 1975; Miller \& Eisenberg, 1988). However, this study expands the literature to examine children's strategies for coping with their own distress.

Along with previous research, these findings support a pattern in which children who generally experience feelings of empathic concern in the face of others' negative emotions show prosocial helping tendencies and are unlikely to respond to others' and their own negative emotions with aggressive-venting behavior (see Eisenberg \& Fabes, 1998). Furthermore, empathic children use developmentally adaptive coping strategies, such as seeking help from others, to manage stressful experiences. On the other hand, children who generally experience high levels of personal distress respond to others' negative emotions with aggressive behavior, show less prosocial helping tendencies, are unlikely to seek support in stressful situations and are unable to manage their own emotionally driven behavior effectively. How children behave in response to their own and others' negative emotions has implications for their social competence and peer acceptance. Responses associated with empathic concern have been linked to children's social competence and acceptance by peers whereas responses associated with personal distress are linked to low levels of social competence and peer rejection (e.g., Denham, Blair, DeMulder, Levitas, Sawyer \& Auerbach-Major, 2003; Dodge, 1983; Eisenberg, Fabes, Murphy, Shepard, Guthrie, Mazsk et al., 1999; Maszk, Eisenberg \& Guthrie, 1999). These findings thus support the hypothesis that because children's empathic concern and personal distress predict different patterns of behavioral responses to stressors, they are indicative of functionally different styles of emotional arousal.

Moreover, by considering maternal EE in relation to children's trait emotional responding and coping, this study extends our understanding of the interactive effects of context and individual characteristics. Specifically, the findings provide partial support for the notion that the emotional context of the family moderates associations between children's individual emotional traits and other outcomes (e.g., Gilliom et al., 2002; Mangelsdorf, Gunnar, Kestenbaum, Lang \& Andreas, 1990). Although the main effects of children's empathic concern and personal distress were the most consistent predictors of coping strategy use in this study, several specific moderational effects emerged. As hypothesized, negative dominant EE moderated associations of child personal distress and coping. Firstly, as both their personal distress and their mothers' negative dominant EE increased, the children's avoidant coping increased. This finding suggests that for children who are prone to experiencing overwhelming negative emotion in response to others' negative affect, relatively high levels of anger or hostili- 
ty in the family context may be a greater stressor than is manageable. In response, these children may learn cognitively or behaviorally to disengage from or avoid sources of stress, which could include avoiding interaction with family members who are displaying negative emotion (see also Volling, 2001). Interestingly, the fact that this interactive effect was found only for parents' reports of children's avoidant coping (but not teachers' reports) may indicate that this avoidance is contextually specific.

The issue of context specificity is further illustrated by the different patterns of intercorrelations among coping strategies for parent and teacher reports of children's coping, as well as the relatively weak correlations between parent and teacher reports. It is likely that, compared with the home environment, teachers' observations occur in environments that are less variable, more structured, produce less extreme emotional situations and place greater constraints on children's behavior. The fact that avoidance and venting are inversely related in the teacher reports, but not in the parent reports, for example, may indicate that children who are able to prevent themselves from using aggressive-venting strategies by avoiding the stressor will do so in a school setting but not in a home setting, producing more diversity in the behaviors observed by parents.

Secondly, mothers' negative dominant EE moderated associations of child personal distress and support seeking. Inspection of this effect suggests that the association between personal distress and support-seeking coping was less negative at higher levels of mothers' negative dominant EE. For children who experience low levels of personal distress, the use of supportseeking coping strategies is not affected by negative dominant EE. However, for children who experience higher levels of personal distress, as the level of negative dominant EE decreases, their use of support-seeking coping strategies also decreases. This finding is similar in pattern to previous research by Valiente, Fabes et al. (2004), indicating that associations between children's stress and constructive coping were more negative at lower levels of their mothers' negative submissive EE.

One possible explanation for these findings is that families in which lower levels of negative emotions are expressed may also discourage the expression of negative affect in children. Thus, although these children experience heightened negative arousal, seeking emotional or instrumental support in stressful situations may be treated as inappropriate. It is also possible that children in family contexts in which little negative emotion is expressed have less opportunity to learn regarding experiencing and resolving negative emotions than do children in which a moderate level of negative emotion is expressed, and this lack of understanding may be particularly difficult for children who experience high levels of negative arousal (Eisenberg et al., 1998). The fact that overall levels of negative dominant EE reported by mothers in this study were relatively low may also have influenced this finding. Although this finding differs from that of Valiente, Fabes et al. (2004) in the type of negative emotion (dominant vs. submissive) that moderated effects between stress and coping, the similar pattern is intriguing and warrants further exploration. As suggested by outlier analyses and follow-up regression models, for future research, including families representing greater variability in levels of negative EE may help to elucidate the nature of these patterns.

In addition, the mothers' negative submissive EE moderated the association between child empathic concern and avoidant coping. In this study, it appeared that as child empathic concern and negative submissive EE increased, children used more avoidant coping strategies. This finding was surprising, given the lack of prior research suggesting that associations of children's empathic concern and coping or emotion regulation are moderated by family EE. 
This, along with the fact that neither of the individual regression slopes was significant, indicates the need for replication before further consideration is given to this finding.

Interestingly, as a direct predictor, the mothers' negative EE was largely unrelated to children's use of coping strategies. Although previous studies of negative family EE and children's emotional behavior have sometimes yielded inconsistent associations, recent findings indicate that negative dominant EE, in particular, may directly predict lower constructive coping in children (Valiente, Fabes et al., 2004). Previous studies examining children's coping in relation to their mothers' reactions to the children's negative emotions have indicated that hostile or punitive (negative dominant) responses are associated with children's aggressive or avoidant behavior. In this study, however, higher maternal negative submissive EE was associated with the children's greater use of aggressive venting (for parents' reports of children's coping only). Although this association was not anticipated, it is somewhat consistent with Garner's (1995) finding that mothers' depression predicted lower emotion regulation abilities in their young children. It may be that a general family emotional climate of pervasive sadness, as with depression, is predictive of lower emotional management capacities in children. This would also be consistent with research linking maternal depression to higher levels of externalizing behaviors in young children (e.g., Greenberg et al., 1999; Moore, Cohn \& Campbell, 2001; Schultz \& Shaw, 2003; Spieker, Larson, Lewis, Keller \& Gilchrist, 1999). Given the inconsistency of this finding and prior research, this finding should be interpreted with caution; however, it warrants attention in future research.

In general, children's support seeking and aggressive venting were better predicted than their avoidant coping in this study. It is possible that this pattern was due to a lower internal reliability of the avoidant coping scales, relative to other scales, which may have attenuated relations of avoidant coping with child emotionality and maternal EE. However, this interpretation seems unlikely, given the consistency with which age predicted avoidant coping, as well the emergence of two interaction effects predicting avoidant coping. That avoidant coping was best predicted by interactions of children's characteristics and their emotional environments suggests that the use of avoidant coping strategies may be more complexly determined than children's use of other types of coping strategies. This conclusion is consistent also with Kliewer, Fearnow, and Miller's (1996) report that slightly older children's avoidant coping was less well predicted by family emotion socialization variables than were support seeking and active coping. An important endeavor in future research will be to account for this complexity in predicting the use of avoidance strategies, as well as to develop a more sophisticated understanding of contextual effects on avoidant coping.

Finally, although not a central focus of this study, it should be noted that age was in several cases a significant predictor of children's use of coping strategies. Specifically, age positively predicted children's use of avoidant coping strategies and negatively predicted their supportseeking coping strategies. This is consistent with a developmental progression that includes both increasing autonomy, and thus decreased reliance on others for assistance, and a more sophisticated understanding and use of cognitive strategies, including avoidance (Compas, 1987; Compas et al., 2001; Losoya, Eisenberg \& Fabes, 1998). Although some prior research suggests that aggressive venting may decrease with age (see Losoya et al., 1998), age was not a significant predictor of children's aggressive venting in this study, possibly due to the relatively young age of children in this study. 
This study has several limitations that should be acknowledged. Firstly, the present study relied heavily on maternal reports of key variables. Secondly, the measure of EE used in the current study may have been an overly general measure of the emotional climate of the home. In addition to assessing the likelihood of emotional expression in specific situations, it is important to understand the overall frequency and intensity of negative emotion, as well as to whom the emotion is directed (Eisenberg et al., 1998). Thirdly, this study assumed that the mothers' reports of their own expressiveness were representative of the overall family emotional climate. For children in two-parent families, failure to include indicators of both parents' emotional expression potentially obscures the nature of associations among the family emotional climate and children's social and emotional behavior. Finally, this study included only concurrent measures of maternal EE and children's emotional responding and coping. We hypothesized that children's use of coping strategies is influenced by their emotional tendencies and by their mothers' negative EE. However, children's coping strategies could influence their tendencies to experience negative affect in response to others' distress, so that children who more effectively enlist coping strategies experience less negative affect in such situations. Similarly, children's inability to cope with negative emotion could evoke specific negative responses in their caregivers and potentially influence the overall emotional climate of the home. It will be important for future researchers to include multiple reporters and observational measures of children's coping and emotional responsiveness, to incorporate more specified measures of EE, and to assess both mothers' and fathers' EE to more accurately account for children's experiences of emotion within the family. To begin to address directionality, future efforts in this area must include longitudinal research across children's preschool and early school years.

Despite these limitations, the current study adds to our understanding of the relations between children's trait vicarious emotional responding and their use of coping strategies. The findings suggest that children's emotional responsiveness is indicative of broader patterns of behavior with implications for its functional value. More broadly construed, this study has implications for the growing body of literature detailing how children's temperament or emotionality may, through their coping, influence their social and behavioral adjustment and peer relationships (e.g., Blair, Denham, Kochanoff \& Whipple, 2004; Lengua \& Long, 2002; Szewczyk-Sokolowski, Bost \& Wainwright, 2005). Moreover, this research adds to a burgeoning understanding of the ways in which EE within the family can differentially influence children's socio-emotional development by interacting with the individual characteristics of children.

\section{References}

Aiken, L. S., \& West, S. G. (1991). Multiple regression: Testing and interpreting interactions. Thousand Oaks, CA: Sage.

Ayers, T. S., Sandler, I. N., West, S. G., \& Roosa, M. W. (1996). A dispositional and situational assessment of children's coping: Testing alternative models of coping. Journal of Personality, 64, 923-958.

Band, E. B., \& Weisz, J. R. (1988). How to feel better when it feels bad: Children's perspectives on coping with everyday stress. Developmental Psychology, 24, 247-253. Batson, C. D. (1991). The altruism question: Toward a social-psychological answer. Hillsdale, NJ: Lawrence Erlbaum Associates, Inc.

Blair, K. A., Denham, S. A., Kochanoff, A., \& Whipple, B. (2004). Playing it cool: Temperament, emotion regulation, and social behavior in preschoolers. Journal of School Psychology, 42, 419-443.

Calkins, S. D., \& Johnson, M. C. (1998). Toddler regulation of distress to frustrating events: Temperamental and maternal correlates. Infant Behavior \& Development, 21, 379-395. 
Carson, J. L., \& Parke, R. D. (1996). Reciprocal negative affect in parent-child interactions and children's peer competency. Child Development, 67, 2217-2226.

Compas, B. E. (1987). Coping with stress during childhood and adolescence. Psychological Bulletin, 101, 393-403.

Compas, B. E., Connor-Smith, J. K., Saltzman, H., Thomsen, A. H., \& Wadsworth, M. E. (2001). Coping with stress during childhood and adolescence: Problems, progress, and potential in theory and research. Psychological Bulletin, 127, 87-127.

Cummings, E. M. (1987). Coping with background anger in early childhood. Child Development, 58, 976-984.

Cummings, E. M., Zahn-Waxler, C., \& Radke-Yarrow, M. (1981). Young children's responses to expressions of anger and affection by others in the family. Child Development, 52, 1274-1282.

Curry, S. L., \& Russ, S. W. (1985). Identifying coping strategies in children. Journal of Clinical Child Psychology, 14, 61-69.

Davis, M. H. (1980). A multidimensional approach to individual differences in empathy. Catalog of Selected Documents in Psychology, 10, 85.

Denham, S. A., Blair, K. A., DeMulder, E., Levitas, J., Sawyer, K., Auerbach-Major, S., et al. (2003). Preschool emotional competence: Pathway to social competence? Child Development, 74, 238-256.

Dodge, K. A. (1983). Behavioral antecedents of peer social status. Child Development, 54, 1386-1399.

Dunsmore, J. C., \& Halberstadt, A. G. (1997). How does family emotional expressiveness affect children's schemas? In K. C. Barrett (Ed.), The communication of emotion: Current research from diverse perspectives (pp. 45-68). San Francisco: Jossey-Bass.

Eisenberg, N., Cumberland, A., \& Spinrad, T. L. (1998). Parental socialization of emotion. Psychological Inquiry, 9, 241-273.

Eisenberg, N., \& Fabes, R. (1991). Prosocial behavior and empathy: A multimethod, developmental perspective. In P. Clark (Ed.), Review of personality and social psychology (Vol. 12, pp. 34-61). Newbury Park, CA: Sage.

Eisenberg, N., \& Fabes, R. (1994). Mothers' reactions to children's negative emotions: Relations to children's temperament and anger behavior. Merrill-Palmer Quarterly, 40, 138-156.

Eisenberg, N., \& Fabes, R. (1998). Prosocial development. In W. Damon (Series Ed.), \& N. Eisenberg (Vol. ed.), Handbook of child psychology: Vol. 4. Social, emotional, and personality development (5th ed., pp. 701-778). New York: Wiley.

Eisenberg, N., Fabes, R. A., Carlo, G., \& Karbon, M. (1992). Emotional responsivity to others: Behavioral correlates and socialization antecedents. New Directions in Child Development, 55, 57-73.

Eisenberg, N., Fabes, R. A., \& Guthrie, I. K. (1997). Coping with stress: The roles of regulation and development. In S. A. Wolchik, \& I. Sandler (Eds.), Handbook of children's coping: Linking theory and intervention (pp. 41-70). New York: Plenum.

Eisenberg, N., Fabes, R. A., Guthrie, I. K., \& Reiser, M. (2000). Dispositional emotionality and regulation: Their role in predicting quality of social functioning. Journal of Personality and Social Psychology, 78, 136-157.

Eisenberg, N., Fabes, R., \& Murphy, B. (1996). Parents' reactions to children's negative emotions: Relations to children's social competence and comforting behavior. Child Development, 37, 2227-2247.

Eisenberg, N., Fabes, R. A., Carlo, G., Troyer, D., Speer, A. L., Karbon, M., et al. (1992). The relations of maternal practices and characteristics to children's vicarious emotional responsiveness. Child Development, 63, 583-602.

Eisenberg, N., Fabes, R., Miller, P. A., Shell, C., Shea, R., \& May-Plumlee, T. (1990). Preschooler's vicarious emotional responding and their situational and dispositional prosocial behavior. Merrill-Palmer Quarter$l y, 36,507-529$.

Eisenberg, N., Fabes, R., Murphy, B., Shepard, S., Guthrie, I. K., Mazsk, P., et al. (1999). Prediction of elementary school children's socially appropriate and problem behavior from anger reactions at age 4-6 years. Journal of Applied Developmental Psychology, 20, 119-142.

Eisenberg, N., Fabes, R. A., Nyman, M., Bernzweig, J., \& Pinuelas, A. (1994). The reactions of emotionality 
and regulation to children's anger-related reactions. Child Development, 65, 109-128.

Eisenberg, N., Fabes, R., Schaller, M., Carlo, G., \& Miller, P. A. (1991). The relations of parental characteristics and practices to children's vicarious emotional responding. Child Development, 62, 1393-1408.

Eisenberg, N., Fabes, R., Shepard, S. A., Guthrie, I. K., Murphy, B. C., \& Reiser, M. (1999). Parental reactions to children's negative emotions: Longitudinal relations to quality of children's social functioning. Child Development, 70, 513-534.

Fabes, R. A., Eisenberg, N., Karbon, M., Troyer, D., \& Switzer, G. (1994). The relations of children's emotion regulation to their vicarious emotional responses and comforting behaviors. Child Development, 65, 1678-1693.

Gamble, W. C. (1994). Perceptions of controllability and other stressor event characteristics as determinants of coping among young adolescents and young adults. Journal of Youth and Adolescence, 23, 65-84.

Garner, P. W. (1995). Toddlers' emotion regulation behaviors: The roles of social context and family expressiveness. The Journal of Genetic Psychology, 156, 417-430.

Gilliom, M., Shaw, D. S., Beck, J. E., Schonberg, M. A., \& Lukon, J. L. (2002). Anger regulation in disadvantaged preschool boys: Strategies, antecedents, and the development of self-control. Developmental Psychology, 38, 222-235.

Greenberg, M., Lengua, L. J., Coie, J. D., \& Pinderhughes, E. E. (1999). Predicting developmental outcomes at school entry using a multiple-risk model: Four American communities. Developmental Psychology, 35, 403-417.

Halberstadt, A. G., Cassidy, J., Stifter, C. A., Parke, R. D., \& Fox, N. A. (1995). Self-expressiveness within the family context: Psychometric support for a new measure. Psychological Assessment, 7, 93-103.

Halberstadt, A. G., Crisp, V. W., \& Eaton, K. L. (1999). Family expressiveness: A retrospective and new directions for research. In P. Philippot, \& R. S. Feldman (Eds.), The social context of nonverbal behavior: Studies in emotion and social interaction (pp. 109-155). New York: Cambridge University Press.

Halberstadt, A. G., \& Eaton, K. L. (2002). A meta-analysis of family emotional expressiveness and children's emotion expressiveness and understanding. Marriage \& Family Review, 34, 35-62.

Hoffman, M. L. (1975). Developmental synthesis of affect and cognition and its implications for altruistic motivation. Developmental Psychology, 11, 607-622.

Kliewer, W. (1991). Coping in middle childhood: Relations to competence, type a behavior, monitoring, blunting, and locus of control. Developmental Psychology, 27, 689-697.

Kliewer, W., Fearnow, M. D., \& Miller, P. A. (1996). Coping socialization in middle childhood: Tests of maternal and paternal influences. Child Development, 67, 2339-2357.

Kliewer, W., \& Sandler, I. (1993). Social competence and coping among children of divorce. American Journal of Orthopsychiatry, 63, 432-440.

Laible, D. J., \& Thompson, R. A. (1998). Attachment and emotional understanding in preschool children. Developmental Psychology, 34, 1038-1045.

Lazarus, R. S., \& Folkman, S. (1984). Stress, appraisal, and coping. New York: Springer.

Lengua, L. J., \& Long, A. C. (2002). The role of emotionality and self-regulation in the appraisal-coping process: Tests of direct and moderating effects. Journal of Applied Developmental Psychology, 23, 471-493.

Losoya, S., Eisenberg, N., \& Fabes, R. A. (1998). Developmental issues in the study of coping. International Journal of Behavioral Development, 22, 287-313.

Mangelsdorf, S., Gunnar, M., Kestenbaum, R., Lang, S., \& Andreas, D. (1990). Infant proneness-to-distress temperament, maternal personality, and mother-infant attachment: Associations and goodness of fit. Child Development, 61, 820-831.

Maszk, P., Eisenberg, N., \& Guthrie, I. K. (1999). Relations of children's social status to their emotionality and regulation: A short-term longitudinal study. Merrill-Palmer Quarterly, 45, 468-492.

Miller, P. A., \& Eisenberg, N. (1988). The relation of empathy and aggressive behavior to externalizing/antisocial behavior. Psychological Bulletin, 103, 324-344.

Miller, P. A., Kliewer, W., Hepworth, J. T., \& Sandler, I. N. (1994). Maternal socialization of children's postdivorce coping: Development of a measurement model. Journal of Applied Developmental Psychology, 
$15,457-487$.

Moore, G. A., Cohn, J. F., \& Campbell, S. B. (2001). Infant affective responses to mother's still face at 6 months differentially predict externalizing and internalizing behaviors at 18 months. Developmental Psychology, 37, 706-714.

Rothbart, M. K., \& Bates, J. E. (1998). Temperament. In W. Damon (Series Ed.) \& N. Eisenberg (Vol. ed.), Handbook of child psychology: Vol 3. Social, emotional, and personality development (5th ed., pp. 105176). New York: Wiley.

Rutter, M. (1996). Stress research: Accomplishments and tasks ahead. In R. J. Haggerty, \& L. R. Sherrod (Eds.), Stress, risk, and resilience in children and adolescents: Processes, mechanisms, and interventions (pp. 354-385). New York: Cambridge.

Schultz, D., \& Shaw, D. S. (2003). Boys' maladaptive social information processing, family emotional climate, and pathways to early conduct problems. Social Development, 12, 440- 460.

Spieker, S. J., Larson, N. C., Lewis, S. M., Keller, T. E., \& Gilchrist, L. (1999). Developmental trajectories of disruptive behavior problems in preschool children of adolescent mothers. Child Development, 70, 443-458.

Spirito, A., Stark, L. J., \& Williams, C. (1988). Development of a brief coping checklist for use with pediatric populations. Journal of Pediatric Psychology, 4, 555-574.

Szewczyk-Sokolowski, M., Bost, K. K., \& Wainwright, A. B. (2005). Attachment, temperament, and preschool children's peer acceptance. Social Development, 14, 379-397.

Thompson, R. A. (1998). Early sociopersonality development. In W. Damon (Ed.), \& N. Eisenberg (Vol. ed.), Handbook of child psychology: Vol. 3. Social, emotional, and personality development (5th ed., pp. 25104). New York: Wiley.

Valiente, C., Eisenberg, N., Shepard, S. A., Fabes, R. A., Cumberland, A. J., Losoya, S. H., et al. (2004). The relations of mothers' negative expressivity to children's experience and expression of negative emotion. Applied Developmental Psychology, 25, 215-235.

Valiente, C., Fabes, R. A., Eisenberg, N., \& Spinrad, T. L. (2004). The relations of parental expressivity and support to children's coping with daily stress. Journal of Family Psychology, 18, 91-106.

Volling, B. L. (2001). Early attachment relationships as predictors of preschool children's emotion regulation with a distressed sibling. Early Education and Development, 12, 185-207. Wertlieb, D., Weigel, C., \& Feldstein, M. (1987). Measuring children's coping. American Journal of Orthopsychiatry, 57, 548-560.

\section{Acknowledgments}

The authors greatly appreciate the assistance of Fanny Baez, Oksana Bendus, Rebecca DunlapMorton, Julie Jones, Deborah Laible, Cindy Nash, Andrea Nichols, Lenna Ontai-Grzebik, Craig Peters, Brooke Talsma, Wen Zhao, and Ying Zurbuchen. Support for this project was provided to the second author by a grant from the American Psychological Association and the John Templeton Foundation.

\section{Note}

1. Tests for multivariate outliers identified three cases for parent-report data and four cases for teacher-report data that were potentially influential. The total number of identified cases was five, as there was some overlap in cases identified for parent- and teacher-report models. These cases were removed, variables recentered, and interaction terms recomputed. Regression models with the reduced samples $(\mathrm{N}=90$ for parent-report data; $\mathrm{N}=82$ for teacher-report data) yielded a pattern of results similar to those presented. All main effects remained unchanged, although some effect sizes were reduced. Interaction effects were reduced and became non-significant. With the removal of the three cases from the regression models using parent-report data, a marginally significant interaction of empathic concern and maternal negative submissive EE to predict children's support-seeking coping emerged $(\mathrm{b}=-.22, p=.05)$. Similarly, we found a marginally significant interaction of empathic concern and maternal negative dominant EE to predict children's teacher-reported avoidant coping $(\mathrm{b}=.24, p=.05)$. Because these effects were only marginally significant, they were not pur- 
sued further. Follow-up analyses indicated that three of the five cases could be considered, in a conservative estimate, outside the upper bound for maternal negative dominant EE. The variable was thus windsorized, trimming these cases to the upper bound value. The variable was recentered and interaction terms recalculated. Results for regression analyses conducted with the windsorized variable were essentially identical to those presented in Tables 3 and 4; only Model 3, predicting parent-reported support seeking from personal distress and maternal negative dominant EE, was slightly reduced and became marginally significant $(\mathrm{b}=-.20, p=$ .06). In the analyses using the windsorized negative dominant EE variable, no multivariate outliers were detected. Patterns of findings were essentially the same with these reduced samples; thus, the full sample was retained for main analyses.

\section{Appendix A. Child Coping Strategies Measure Items}

Scale Item

Avoidance

Support seeking

Keep his/her feelings to him/herself.

Stay away from the problem or situation.

Do something else to forget about the problem.

Keep trying different things. ${ }^{\text {a }}$

Pretend it did not happen.

Tell an adult what happened.

Try to figure out how to fix the problem.

Try to negotiate a solution.

Seek comfort from an adult.

Ask an adult for help.

Ask a friend for help.

Talk about ways to solve the problem.

Ask questions to get more information about the problem

or situation.

Aggressive venting

Yell or call someone a name.

Hit, kick, or throw something.

${ }^{\text {a }}$ Item deleted from teacher-report avoidance scale. 